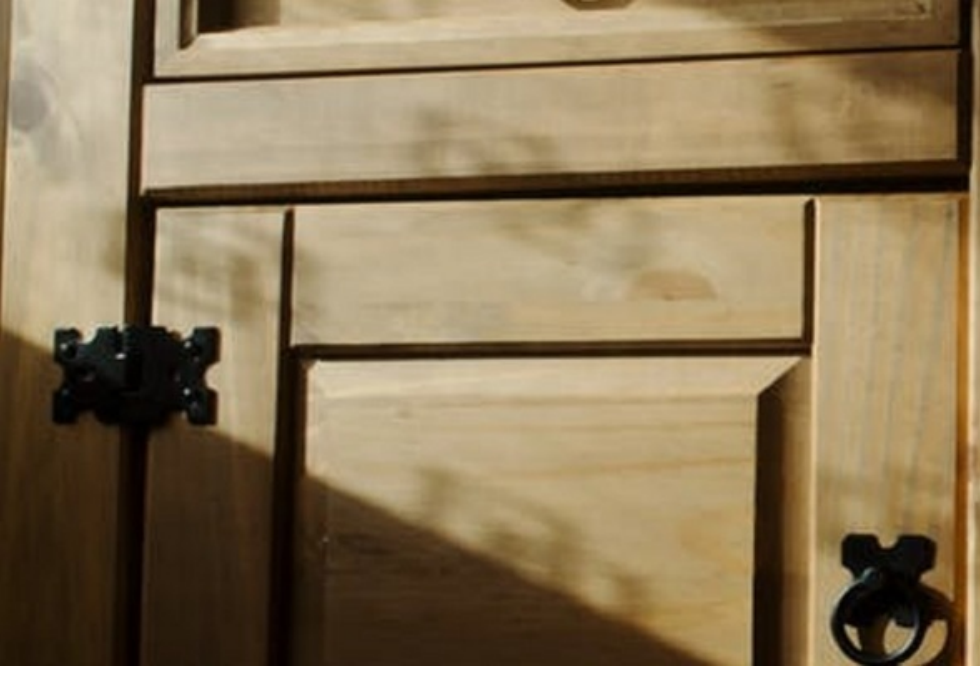

BIO-SIEL for the classical?

Authors: Leander Hotaki

Submitted: $\quad$ 8. October 2018

Published: $\quad$ 11. October 2018

Volume: 5

Issue: 8

Languages:

Keywords:

\title{
Abstract:
}

DOI: $\quad$ 10.17160/josha.5.8.478

Leander Hotaki is since 2010 the director of the German program called "Albert Konzerte" which is a program encharged of making possible to bring the greatest artist of the World to Freiburg and to make the most wonderful concerts in the south-west of Germany. In fact, he also promotes the work of the best students in the field of dramaturge or music in many universities in Germany and writes columns about different topics around music and musicians. This time he writes about the possibility of making an ecological music work.

JOSHA

josha.org
Journal of Science,

Humanities and Arts

JOSHA is a service that helps scholars, researchers, and students discover, use, and build upon a wide range of content 


\section{BIO-SIEGEL FÜR DIE KLASSIK?}

Auch auf dem Felde klassischer Musik hat ökologisches Denken in Kategorien wie „Bio“ und „Nachhaltigkeit“ längst Einzug gehalten bzw. haben sich Wandlungen vollzogen, die ökologisch sinnvoll sind: In Bühnenanweisungen, also der Listung der Wünsche des Künstlers beim Konzert, liest man bei den Bestellungen von Obst, Gemüse oder Säften immer öfter den Zusatz „bitte Bio“; einige Unverbesserliche freilich bestellen weiterhin nachgewiesen gesundheitsschädigende Getränke wie Coca Cola, mancher Genießer wenigstens ein Glas Wein (wir reichen natürlich grundsätzlich badischen).

Auf der Bühne ersetzen zunehmend Tablets die schwere Notenausgabe auf dem Pult der Musiker ökologisch wie finanziell sehr sinnvoll, denn wenn beispielsweise ein amerikanisches Orchester mit 100 Musikern eine Europatournee mit sieben Konzerten macht, mit drei verschiedenen Werken mit einem Partiturgewicht von jeweils zwei Kilo pro Ausgabe, fallen anstelle der leichten Tablets 600 Kilo Notengepäck an, sowohl zweimal transatlantisch als auch sechsmal innereuropäisch zu transportieren teuer und ökologisch unverträglich. Gewiss, die Tablets im Konzert verbrauchen (hoffentlich Bio-) Strom, aber die CO2-Bilanz der Tablets dürfte auf jeden Fall besser sein als der Partiturtransport über tausende von Kilometern. Auch Reiserouten der Künstler und Orchester, so jedenfalls mein Eindruck, werden in letzter Zeit ökologisch sinnvoller zusammengestellt, mit weniger Zick-Zack-Routen und mehr sinnvollem Routing. Sowohl beim Notengepäck als auch bei den Routen freilich dürfte in den meisten Fällen nicht der ökologische Faktor für die Umstellung ausschlaggebend sein, sondern die finanzielle Ersparnis, in Zeiten immer knapper werdender Gelder für die Kunst ein großes Problem. Dennoch spielt ein Nachhaltigkeitsdenken bei diesen Entscheidungen bei den Intendanzen und Musikern zunehmend mit, und man darf gespannt sein, ob Musiker oder Orchester sich in Zukunft ökologisch zertifizieren lassen. Meine Einschätzung: das wird mittelfristig kommen, da ökologisch-nachhaltiges Handeln immer stärker Teil eines positiven Images wird, auch in der klassischen Musik.

\section{Dr. Leander Hotaki}

